\title{
Effect of muscle exercise with an oral screen on lip function
}

\author{
Urs Thüer and Bengt Ingervall \\ Orthodontic Clinic, University of Bern, Switzerland
}

SUMMARY The study aimed at evaluating how training of the lips with an oral screen affects the strength of the lips and the pressure of the lips on the teeth. In addition, the effect of the treatment with an oral screen on the dentition was studied.

The treatment and lip training programme was instituted for 9 months in 16 children, 7-11 years old, with protruding maxillary incisors. The effect on the dentition was studied on dental casts made before and at the end of the treatment, and 5 months thereafter, as well as on lateral cephalograms.

The lip strength was recorded with a dynamometer. The pressure from the lips on the upper and lower central incisors at rest, and during chewing and swallowing was measured with an extraoral pressure transducer incorporated in a water-filled system with an intra-oral measuring point. Measurements of lip strength and pressure were made regularly before and during the treatment; and continued for up to 10 months thereafter.

The treatment resulted in a decrease of the overjet and upper dental arch length, but with some relapse after the treatment. The strength of the lips increased during the treatment, but decreased afterwards. The pressure from the lips on the teeth at rest and during swallowing was unaffected by the lip training. The pressure from the lower lip during chewing increased temporarily during the treatment period.

\section{Introduction}

Previous studies by one of the present authors have dealt with the effect of lip training on the dentition, and on the morphology and function of the lips without (Ingervall and Eliasson, 1982) and with the use of an oral screen (Owman-Moll and Ingervall, 1984). It was found that lip training exercises in children with incompetent lips beneficially influenced the morphology and function of the lips, but had no demonstrable effect in the correction of proclined maxillary incisors (Ingervall and Eliasson, 1982). The effect on the lip morphology was an increase of the upper and lower lip heights, and a reduction of the interlabial gap. Because of the lack of effect on tooth position, and the considerable effort required on the part of both the dentist and the child, a second study was performed to investigate whether an oral screen would be more effective for lip training.

The use of an oral screen resulted in the retroclination of proclined maxillary incisors simuiltaneously with a proclination of the lower incisors. The latter effect was ascribed to the isolation of the lower incisors from the lip pressure by the oral screen. The treatment with an oral screen did not substantially influence lip morphology or the activity of the lip muscles.

Apart from the changes in tooth position, the most marked effect of the oral screen combined with lip training was a substantial increase in the maximal strength of the lips. The lip strength as measured with a so-called pom-meter (Posen, 1972, 1976) increased by more than 50 per cent. It is not known whether the increased strength of the lips also means an increase of the pressure from the lips on the teeth. If so, this could be of advantage with regard to the stability of the correction of maxillary incisor proclination with an oral screen. The aim of this study was primarily to investigate whether the increase in lip strength attainable with an oral screen also affects the pressure from the lips on the teeth. 


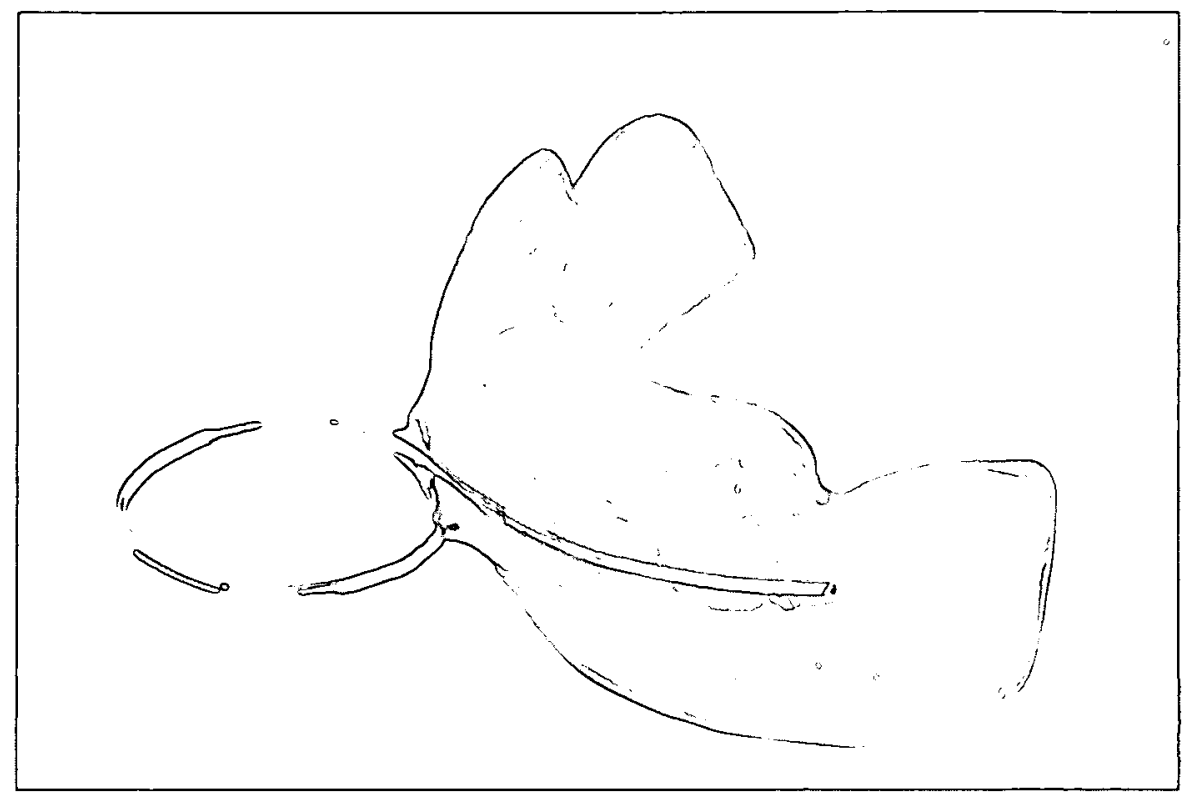

Figure 1 Oral screen.

\section{Subjects and methods}

Sixteen children ( 10 boys and 6 girls) were included in the study. Their median age was 9 years, 3 months (range 6 years, 8 months to 11 years, 2 months). All children had incompetent lips, a short upper lip and proclined maxillary incisors, and were treated with an oral screen. Nine children had a neutral and three a distal occlusion, while in four children the intermaxillary relation was neutral on one side and distal on the other.

\section{Treatment with the oral screen}

The custom-made acrylic screen was extended backward to the first permanent molars, and filled the upper and lower buccal folds. It was in contact with the maxillary incisors, but a small gap (1-2 mm) existed between the appliance, and the other teeth and the alveolar process. In the midline, it was equipped with a metal loop which extended between the lips (Fig. 1).

The screen was used at night and the children were also told to perform lip training exercises for 10 minutes during the daytime. For the exercise, the child was instructed to pull forwards on the loop while trying to resist the force maximally by tightening the lips (Fig. 2). The time for the exercise was divided into three periods with 3 minutes in the morning and at mid-day and 4 minutes in the evening. The children came to the clinic for check-ups once a month, when they were encouraged to continue with the lip-training exercises, and the oral screen was adjusted when necessary by the addition of guttapercha to ensure contact with proclined maxillary incisors only. The treatment was continued for 8-10 months (median 9 months).

\section{Facial morphology}

Before the start of the treatment (median 1, range $0-5$ months) and 14 months thereafter (median 14 , range 12-16 months) profile cephalograms and dental casts were made.

The profile cephalograms were taken with the mandible in the intercuspal position and with relaxed lips, and included a linear enlargement of 3.3 per cent. In the cephalometric analysis, the reference points and planes shown in Figs 3 and 4 were used. The morphology of the face and the inclination of the incisors as well as the lip position and morphology were evaluated with the variables given in Table 2 .

On the dental casts, overjet and overbite were measured by the method of Lundström (1948). In addition, the width and length of the dental arches were measured as shown in Fig. 5 with special sliding calipers, to the nearest $0.1 \mathrm{~mm}$. In 


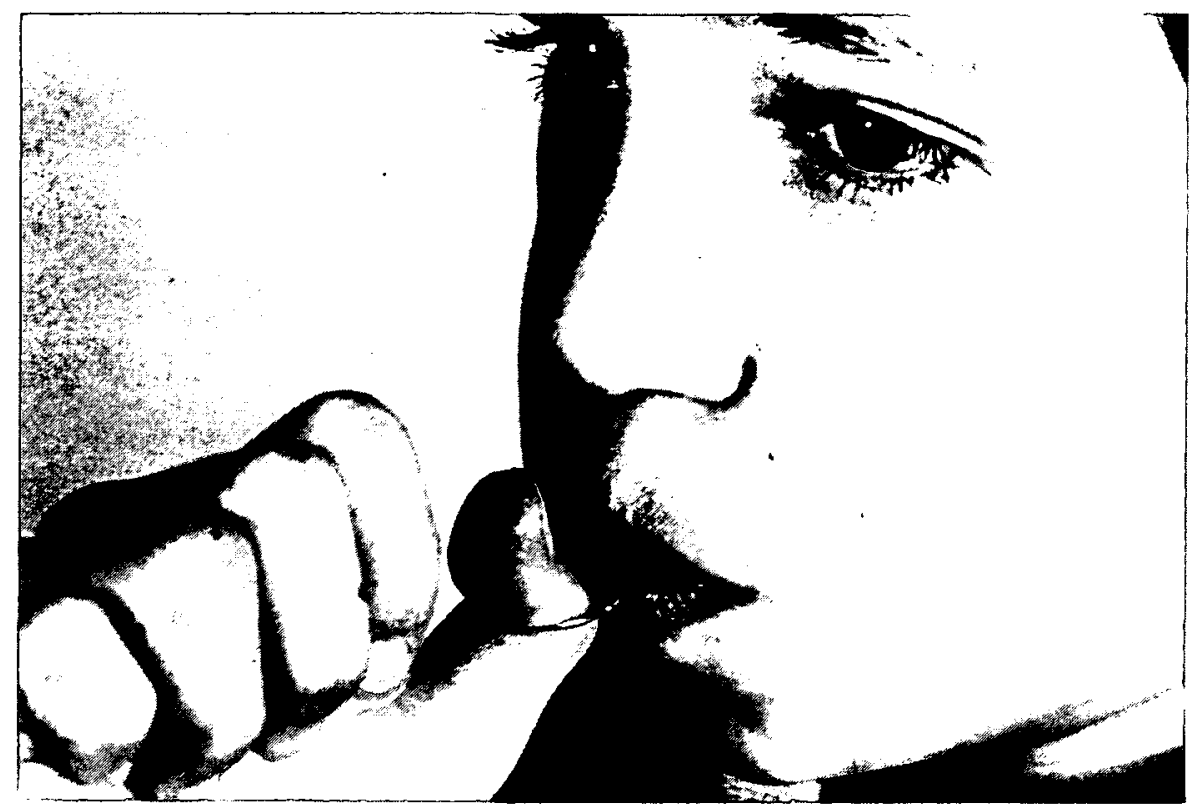

Figure 2 Lip training with the oral screen.

addition to the dental casts made before the treatment (cast I) and after 14 months (cast III), a cast was also made at the end of the use of the oral screen, i.e. after 9 months (cast II).

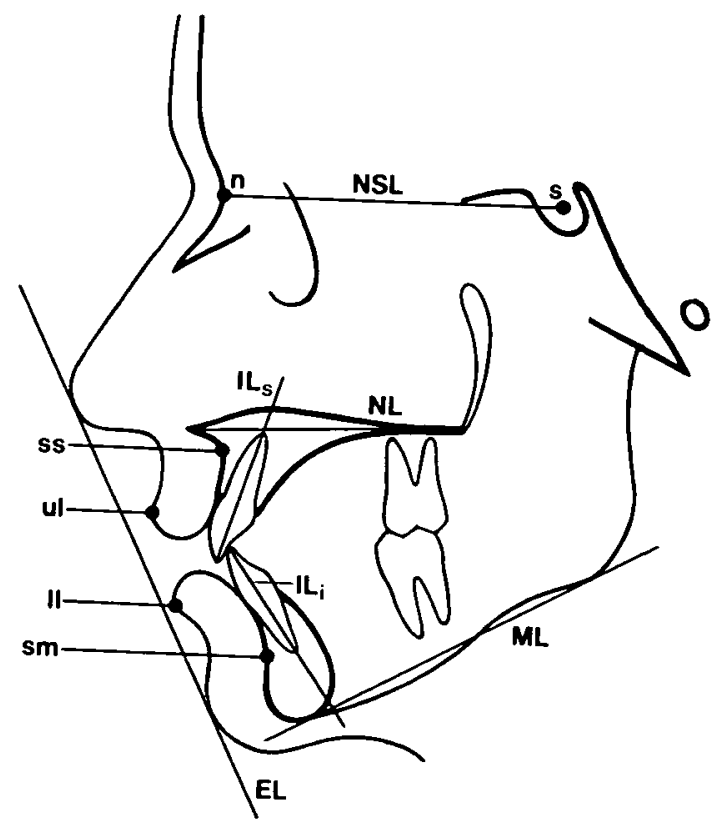

Figure 3 Reference points and lines used in the cephalometric analysis.

\section{Lip strength}

The strength of the lips was assessed with a pommeter as described by Posen. The same instrument has been used in earlier investigations (Ingervall and Janson, 1981; Janson and Ingervall, 1982; Owman-Moll and Ingervall, 1984; Thüer and Ingervall, 1986). It consists of a mouthpiece connected to a dynamometer and measures the maximum force (in grams) with which the lips can resist the mouthpiece being pulled loose from the grip between the upper and lower lips (Fig. 6). The procedure was as earlier described, i.e. the median value of five recordings was used as the measurement of lip strength.

Lip strength was measured twice, at different sessions, before the start of the treatment, at each control visit, and thereafter at monthly intervals up to 13 months after the start of the treatment. A final measurement was made 4-11 months (median 9 months) after the end of the treatment.

\section{Lip function}

The function of the lips was evaluated by simultaneous electromyographic measurement of the muscle activity and of the pressure from the lips on the incisors.

For the electromyography, a DISA electromyograph was used with bipolar surface elec- 

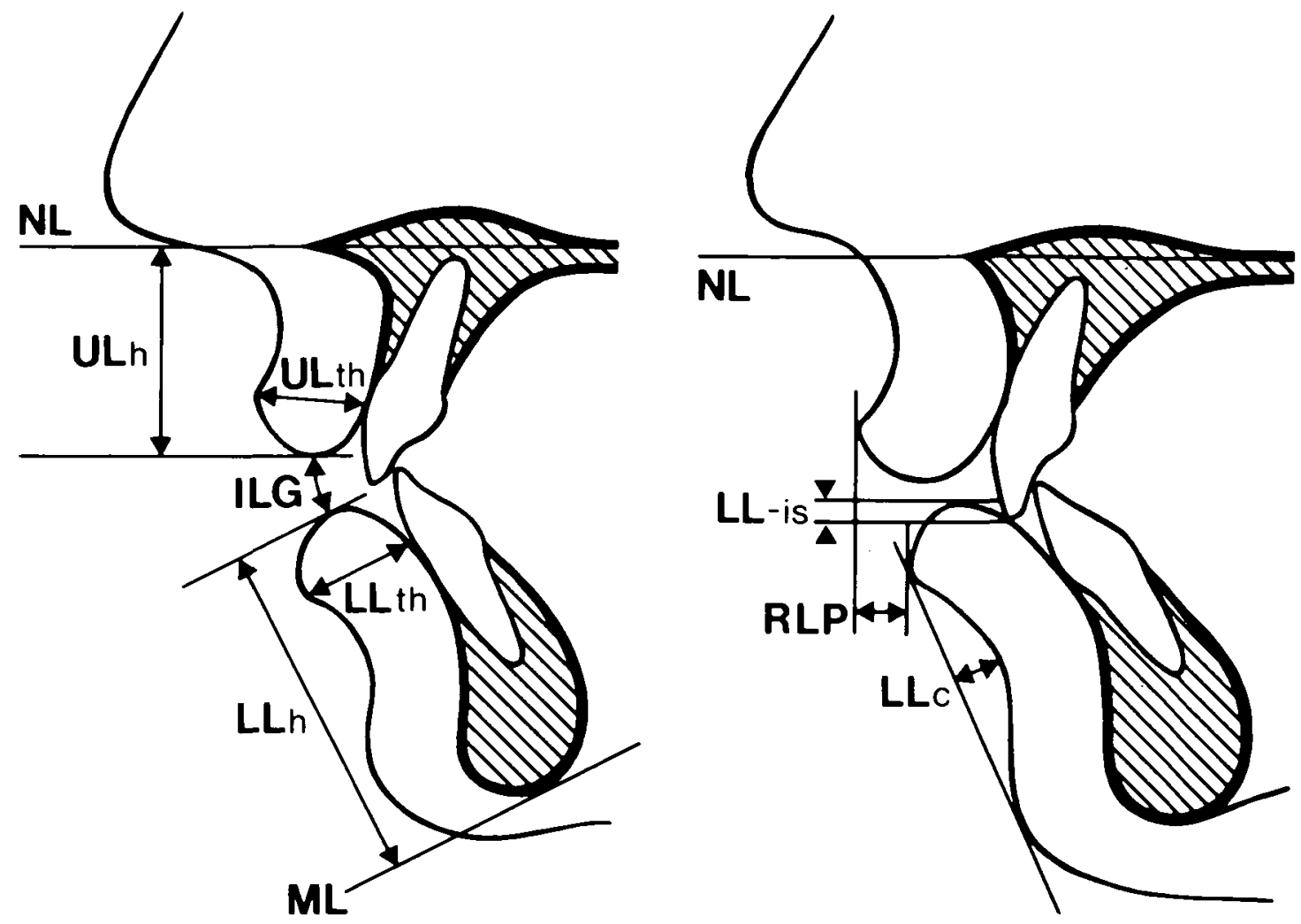

Figure 4 (a and b) Measurements of lip morphology and position on profile cephalogram.

trodes on the upper and lower lips, and on the right masseter muscle. The masseter activity was recorded to assess the phase of the chewing cycle and to identify acts of swallowing.

The lip pressure was measured in the midline between the upper and lower central incisors, respectively. The measuring points were on the labial surfaces of the teeth, level with the tip of the gingival papilla (Fig. 7). The pressure-mea- suring system consisted of an extra-oral pressure transducer incorporated in a water-filled system with an intra-oral mouthpiece at the position where the lip pressure was recorded (Fig. 8). This method, like the electromyographic procedure, has been extensively described in earlier studies in which the same equipment was used (Thüer et al., 1985; Thüer and Ingervall, 1986).

Two recordings of lip muscle activity and of lip
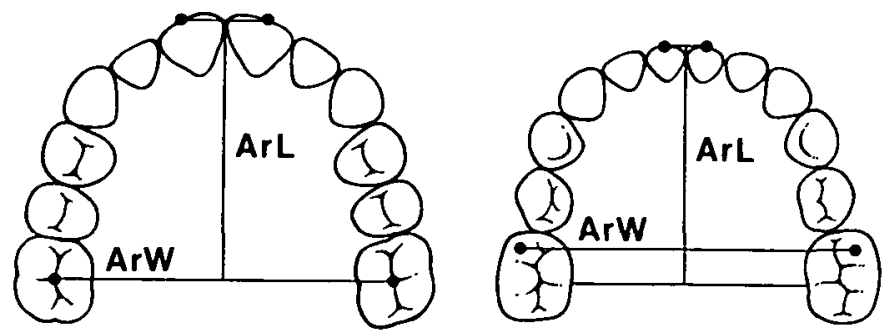

Fịgure 5 Measurements of dental arch width and length on casts. 


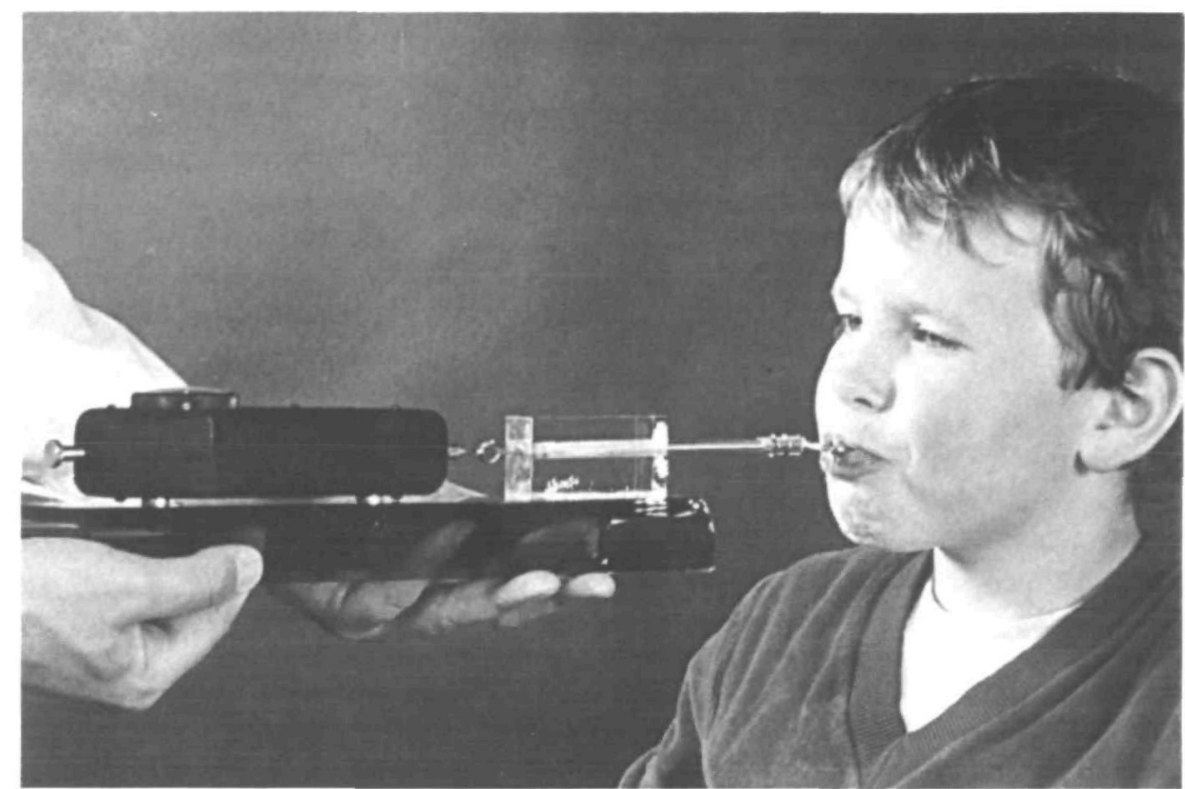

Figure 6 Measurement of lip strength with the pom-meter.
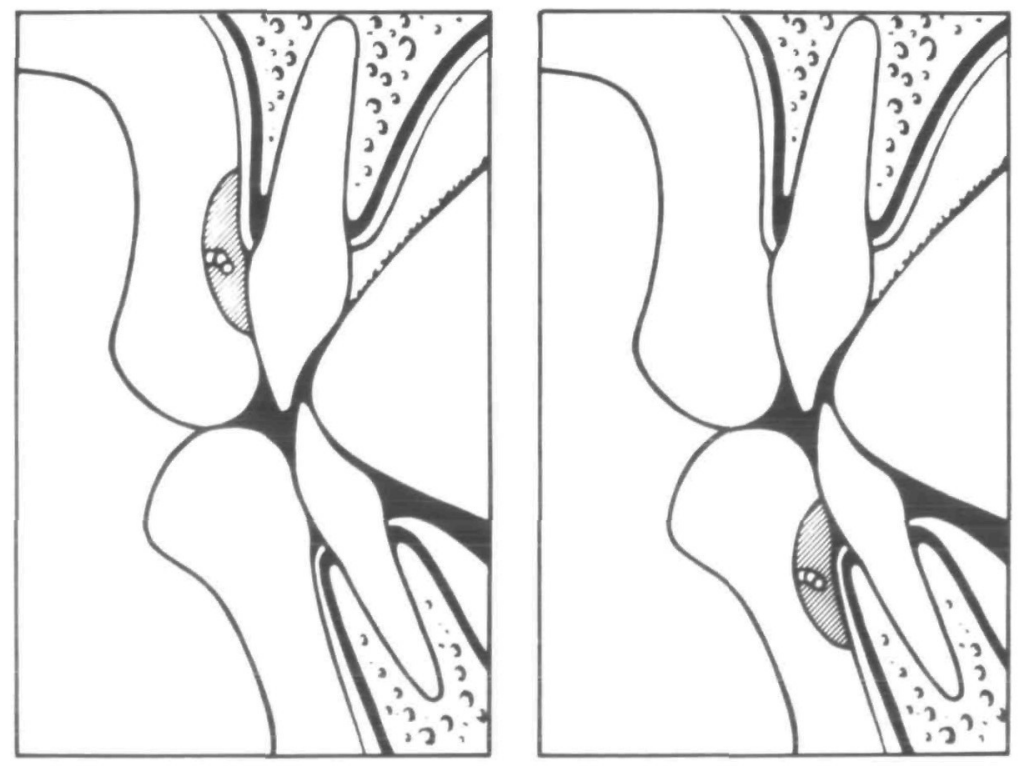

Figure 7 Schematic view of the measuring point for lip pressure on the upper and lower incisors.

pressure were made at different sessions before the start of the treatment, at every second control visit, and thereafter bimonthly until 13 months after the start of the treatment. A final recording was made 7-11 months (median 10 months) after the end of the treatment.

At each recording session, simultaneous recordings of upper and lower lip pressure, and the muscle activity of both lips were made:

(1) in the rest position;

(2) during repeated chewing and swallowing of crispbread;

(3) a new recording in the rest position. 


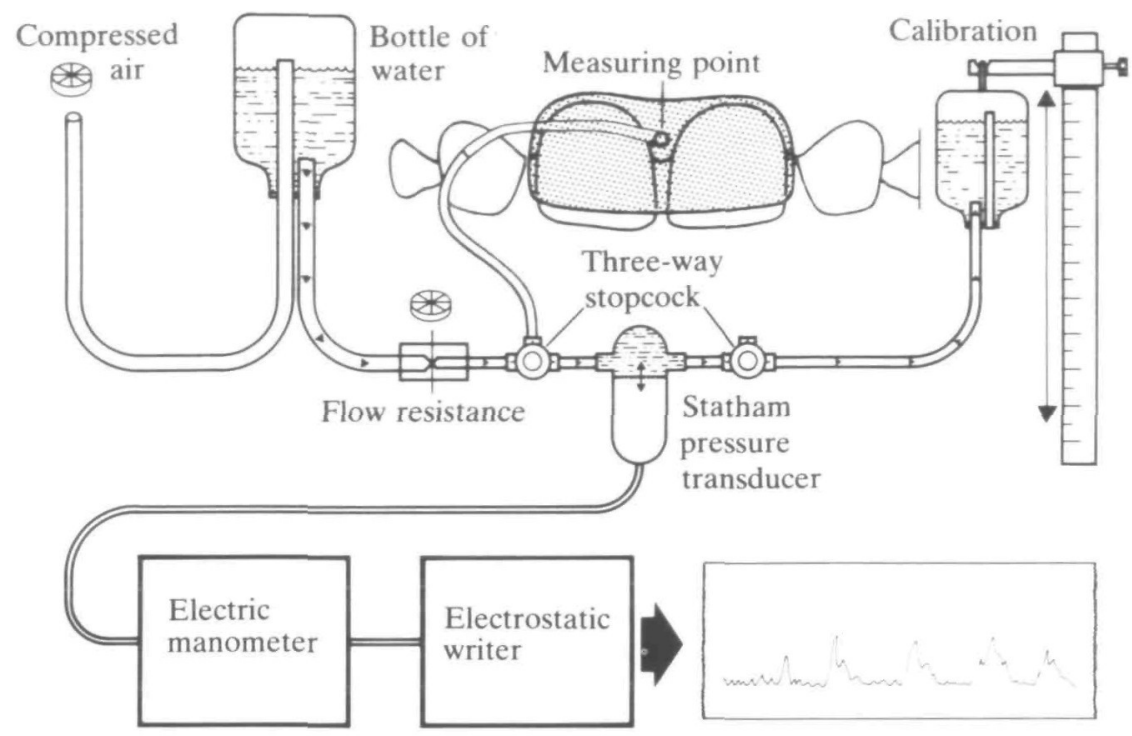

Figure 8 Lip pressure-measuring system.

The same sequence was repeated for the measurement of the lower lip pressure.

Analysis of lip pressure and muscle activity recordings

The resting lip pressure was measured on the recordings when the EMG activity of the lip in question was minimal for at least 5 seconds. The average of the two recordings (a and c) was calculated.

The maximum lip pressure during the opening and closing phases of the chewing cycle (determined from the EMG of the masseter muscle) was measured in six randomly selected chewing cycles in each of two acts of chewing. It was measured during two acts of swallowing (terminating the two acts of chewing). The averages of the maximum lip pressure during the two recordings of swallowing and the 12 cycles of chewing were calculated.

An example of the recording of muscle activity and the pressure from the lower lip during swallowing is given in Fig. 9.

\section{Statistical methods}

Differences between variables recorded on different occasions were tested with Wilcoxon's matched-pairs signed-ranks test.

Spearman rank-correlation coefficients were calculated to evaluate relationships between selected variables.

\section{Results}

The biometric variables derived from the dental casts before treatment (cast I), at the end of the treatment with the oral screen (cast II) and at the examination after 14 months (cast III) are given in Table 1.

As can be seen from Table 1, there was a significant decrease of the overjet and the upper arch length from cast I to cast II, followed by a significant increase from cast II to cast III. The overbite increased from cast I to cast II, but then did not change significantly. The upper and lower arch widths increased significantly from cast I to cast II and in the upper arch continued to increase to cast III, with no significant change in the lower jaw. The lower arch length was unchanged during the period of observation.

No cephalometric variable related to the lips changed significantly during the period of observation (Table 2). The inclination of the incisors did not change significantly. There was an average increase of the angle $s-n-s m$ by $0.8^{\circ}$ and a decrease of the angle ss- $n-s m$ by $1.2^{\circ}$. The average decrease of the angles NSL/ML by $0.9^{\circ}$ and NL/ML by $1.3^{\circ}$ were significant.

The results of the measurements of the lip strength before treatment (mean of two determi-. nations on different occasions), at the end of the treatment with the oral screen and at the followup registration (4-11 months, median 9 months, 
Table 1 Median and range (in $\mathrm{mm}$ ) of variables measured on dental casts.

\begin{tabular}{|c|c|c|c|c|c|c|}
\hline & \multicolumn{2}{|l|}{ Cast I } & \multicolumn{2}{|l|}{ Cast II } & \multicolumn{2}{|l|}{ Cast III } \\
\hline & Median & Range & Median & Range & Median & Range \\
\hline Overjet & 6.3 & $4.5-9.5$ & $4.3^{* * *}$ & $2.0-8.5$ & $5.0^{*}$ & $3.0-8.0$ \\
\hline Overbite & 0.8 & $-4.5-5.0$ & $2.0^{*}$ & $-4.0-5.0$ & 2.5 & $-2.0-5.0$ \\
\hline Upper arch width & 45.5 & $39.8-49.7$ & $46.4^{* *}$ & $39.4-50.7$ & $46.7^{*}$ & $40.7-51.2$ \\
\hline Lower arch width & 46.9 & $42.0-51.5$ & $47.6^{* *}$ & $42.3-52.5$ & 48.0 & $42.5-52.5$ \\
\hline Upper arch length & 36.5 & $34.0-40.5$ & $35.0^{* * *}$ & $32.5-39.0$ & $36.0^{* * *}$ & $33.5-40.5$ \\
\hline Lower arch length & 31.7 & $30.0-34.5$ & 32.3 & $30.0-36.0$ & 32.5 & $30.0-35.5$ \\
\hline
\end{tabular}

*0.01<P<0.05, ${ }^{* *} 0.001<P<0.01,{ }^{* * *} P<0.001$; indicates significant difference from previous measurement.

Table 2 Mean and standard deviation of cephalometric variables before treatment and 5 months after the end of the treatment.

\begin{tabular}{|c|c|c|c|c|c|}
\hline \multirow[b]{2}{*}{ Variables } & \multicolumn{2}{|c|}{$\begin{array}{l}\text { Before } \\
\text { treatment }\end{array}$} & \multicolumn{2}{|c|}{$\begin{array}{l}\text { Five } \\
\text { months } \\
\text { after the } \\
\text { end of the } \\
\text { treatment }\end{array}$} & \multirow{2}{*}{$\begin{array}{l}\text { Significance } \\
\text { of difference }\end{array}$} \\
\hline & Mean & SD & Mean & SD & \\
\hline \multicolumn{6}{|c|}{ Skeleton and dentition (degree) } \\
\hline$s-n-s s$ & 81.0 & 4.0 & 80.6 & 4.4 & \\
\hline$s-n-s m$ & 75.6 & 3.8 & 76.4 & 3.8 & $0.001<P<0.01$ \\
\hline ss-n-sm & 5.4 & 2.7 & 4.2 & 2.8 & $0.001<P<0.01$ \\
\hline NSL/NL & 5.7 & 2.0 & 6.2 & 2.0 & \\
\hline $\mathrm{NSL} / \mathrm{ML}$ & 35.3 & 5.0 & 34.4 & 5.1 & $0.01<P<0.05$ \\
\hline NL/ML & 29.5 & 4.4 & 28.2 & 4.5 & $0.01<P<0.05$ \\
\hline ILs/NL & 113.5 & 4.3 & 114.2 & 3.8 & \\
\hline lLi/ML & 97.5 & 5.6 & 98.0 & 3.6 & \\
\hline \multicolumn{6}{|c|}{ Soft tissue $(\mathrm{mm})$} \\
\hline EL-ul & 1.3 & 1.9 & 0.3 & 2.7 & \\
\hline EL-ll & 2.3 & 2.4 & 1.7 & 3.0 & \\
\hline ULh & 24.5 & 3.7 & 23.9 & 3.2 & \\
\hline ULth & 11.9 & 1.5 & 11.9 & 2.1 & \\
\hline LLh & 40.9 & 4.3 & 39.6 & 6.0 & \\
\hline LLth & 14.4 & 1.9 & 14.0 & 2.3 & \\
\hline ILG & 3.4 & 3.7 & 4.9 & 4.6 & \\
\hline LL-is & 0.4 & 2.3 & -0.7 & 2.8 & \\
\hline RLP & 5.8 & 2.8 & 5.5 & 3.0 & \\
\hline LLc & 5.4 & 1.4 & 5.2 & 1.3 & \\
\hline
\end{tabular}

after the end of treatment) are given in Table 3. As is evident from Table 3, there was an increase of the lip strength during the period of treatment which was, however, followed by a decrease after the treatment. The development of the lip strength over time is shown in Fig. 10.

The lip pressures measured before treatment
Table 3 Median and range (in grams) of lip strength before and at the end of treatment, and at the followup examination.

\begin{tabular}{llr}
\hline & Median & \multicolumn{1}{c}{ Range } \\
\hline Before treatment & 145 & $75-232$ \\
End of treatment & $245^{* * *}$ & $130-350$ \\
Follow-up examination & $190^{*}$ & $120-270$ \\
\hline
\end{tabular}

${ }^{*} 0.01<P<0.05 ;{ }^{* * *} P<0.001$; indicates significant difference from previous measurement.

(mean of two recordings on different occasions), at the end of the treatment and at the follow-up examination (7-11 months, median 10 months, after the end of treatment) are given in Table 4.

There were no significant changes during the period of observation in the resting lip pressures, or in the pressure from the lips during swallowing, or the pressures from the upper lip during chewing. The pressures from the lower lip during chewing increased during the treatment, but then decreased again to the follow-up examination.

\section{Discussion}

The treatment with an oral screen resulted in a decrease of the overjet and the upper dental arch length. This is in line with the results obtained in the previous study of the immediate effect of treatment with an oral screen (Owman-Moll and Ingervall, 1984). The improvement was, however, partly lost during the control period after treatment. This is probably the reason why no change in the incisor inclination or in the soft tissue morphology was found when comparing the findings before treatment and the second 

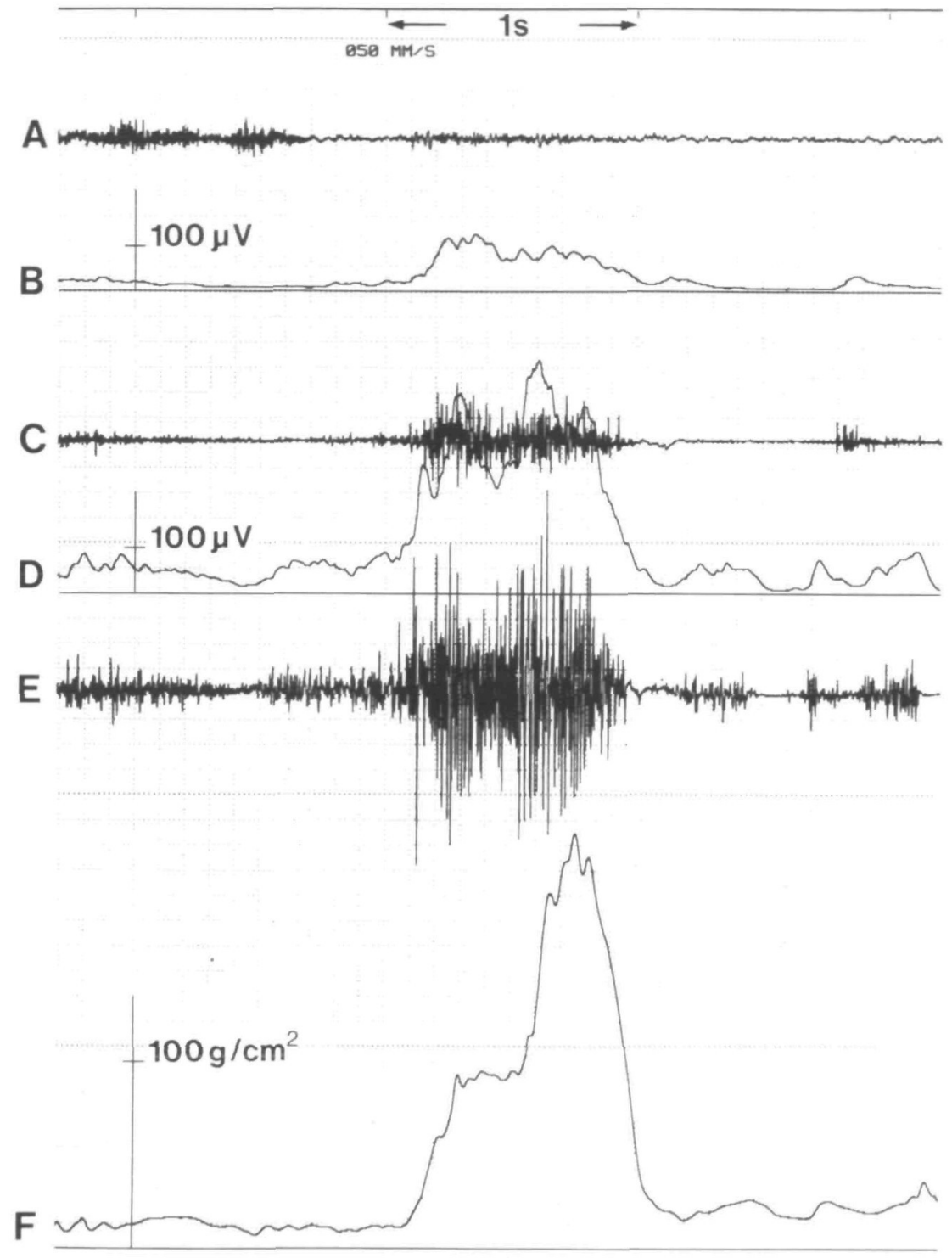

Figure 9 Electromyographic and lip pressure recording of swallowing. (A) Direct recording of masseter muscle activity. (B) Mean voltage recording of upper lip activity. (C) Direct recording of upper lip activity. (D) Mean voltage recording of lower lip activity. (E) Direct recording of lower lip activity. (F) Lip pressure.

cephalogram made 5 months after treatment. It is also worth mentioning that no growth changes of the lips were demonstrable. This had been expected from previous studies (Vig and Cohen, 1979; Owman-Moll and Ingervall, 1984).

The changes in the dental arch widths found during the period of observation probably result from normal growth and development and can- not be ascribed to the treatment (Moyers et al., 1976; Owman-Moll and Ingervall, 1984). The same is true of the changes in mandibular prognathism and inclination (Riolo et al., 1974; Sinclair and Little, 1985). The increase in overbite during the treatment may partly be ascribed to normal development (Fleming, 1961; Moyers et al., 1976; Bergersen, 1988), but is also due to 


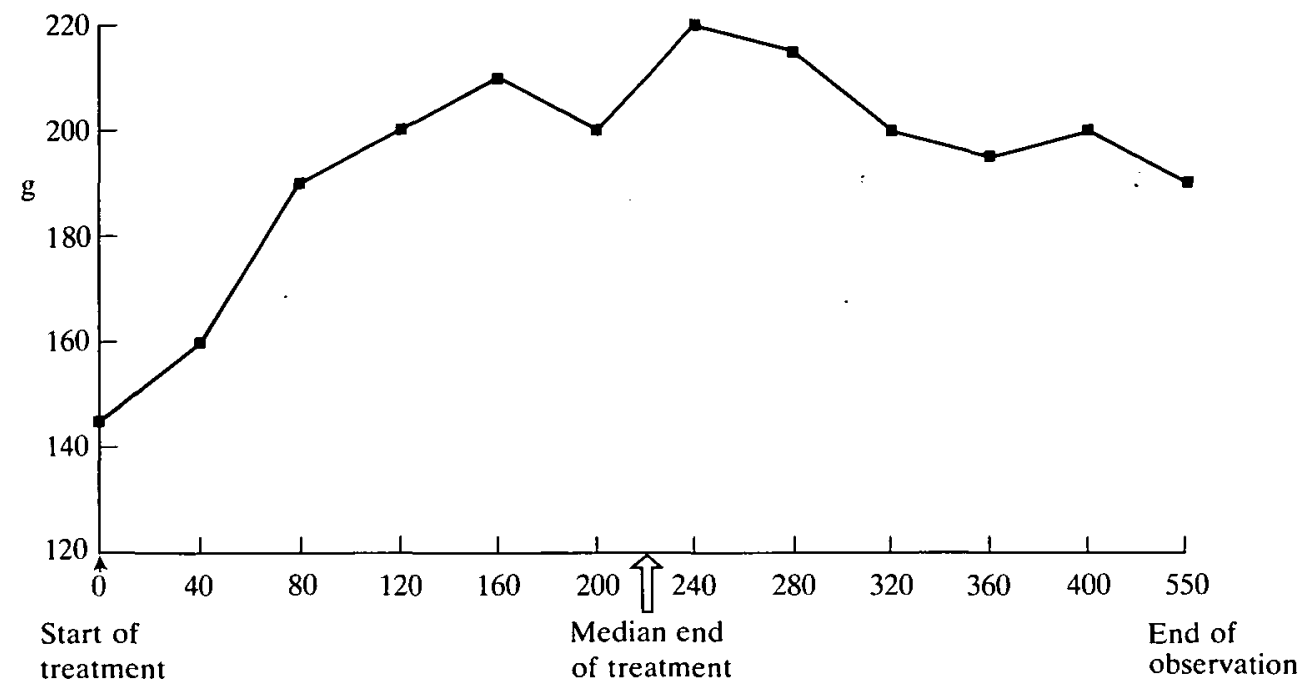

Figure 10 Median values for lip strength during the period of observation.

Table 4 Median and range (in $\mathrm{g} / \mathrm{cm}^{2}$ ) of the lip pressure before and at the end of treatment and at the follow-up examination.

\begin{tabular}{|c|c|c|c|c|c|c|}
\hline & \multicolumn{2}{|c|}{ Before treatment } & \multicolumn{2}{|c|}{ End of treatment } & \multicolumn{2}{|c|}{ Follow-up } \\
\hline & Median & Range & Median & Range & Median & Range \\
\hline \multicolumn{7}{|l|}{ Rest } \\
\hline Upper lip & 4.9 & $-1.7-13.6$ & 5.2 & $-1.6-12.7$ & 3.7 & $-4.6-11.9$ \\
\hline Lower lip & 11.7 & $1.1-31.2$ & 12.5 & $-2.2-30.0$ & 12.8 & $4.5-42.7$ \\
\hline \multicolumn{7}{|l|}{ Chewing } \\
\hline \multicolumn{7}{|l|}{ Upper lip } \\
\hline Opening phase & 44.1 & $6.1-172.2$ & 49.1 & $8.3-155.7$ & 49.0 & $3.2-164.1$ \\
\hline Closing phase & 45.4 & $3.2-187.3$ & 47.2 & $7.3-133.1$ & 54.3 & $2.9-128.3$ \\
\hline \multicolumn{7}{|l|}{ Lower lip } \\
\hline Opening phase & 121.3 & $37.0-415.9$ & $189.4^{*}$ & $65.9-449.9$ & $161.8^{*}$ & $16.8-409.4$ \\
\hline Closing phase & 94.6 & $29.7-428.3$ & $168.5^{* *}$ & $63.9-414.3$ & $151.5^{* *}$ & $29.0-277.2$ \\
\hline \multicolumn{7}{|l|}{ Swallowing } \\
\hline Upper lip & 81.1 & $16.7-177.2$ & 92.4 & $37.5-274.6$ & 75.3 & $4.1-224.9$ \\
\hline Lower lip & 258.1 & $67.9-601.7$ & 313.3 & $98.7-542.7$ & 342.9 & $59.1-539.3$ \\
\hline
\end{tabular}

the retraction of the maxillary incisors by the treatment.

The average lip strength before treatment was markedly lower than normal. It increased during treatment to a level above the normal for age and at the follow-up examination conformed to normal (Posen, 1976; Ingervall and Janson,
1981; Thüer and Ingervall, 1986). The lip training, thus, had a beneficial influence on the lip strength provided that it will not decrease further with time. The increase of the lip strength from training with an oral screen closely conforms to the results of the previous investigation (Owman-Moll and Ingervall, 1984). A new find- 
ing is that the lip strength will decrease again when the lip training is discontinued. This was not previously studied. It is possible that the variations in the lip strength are due to some extent to the variations in overjet and dental arch length as a negative correlation with these parameters was previously found (Thüer and Ingervall, 1986).

The average upper lip resting pressure on the teeth in this study was higher than that in previous studies using the same method, where median values of $2 \mathrm{~g} / \mathrm{cm}^{2}$ were found (Thüer $e t$ al., 1985; Thüer and Ingervall, 1986).

A negative upper lip resting pressure was found before and at the end of treatment in four children (25 per cent) and at the follow-up recording in three children. This proportion of children with a negative upper lip resting pressure coincides with that found in a larger sample (26 per cent; Thüer and Ingervall, 1986).

The average lower lip resting pressure was of the same magnitude as in the previous studies (9 $\mathrm{g} / \mathrm{cm}^{2}$ ). A negative lower lip resting pressure was found only at the recording after treatment in two children. This low prevalence of negative lower lip resting pressure is also in accordance with previous results. For a discussion of negative resting pressure see Thüer et al. (1985).

The reason for the higher upper lip resting pressure in the present study may be the increased overjet of the subjects as a positive correlation with the overjet has been demonstrated (Thüer and Ingervall, 1986).

The pressures from the upper lip during chewing conformed well to previous results. The lower lip chewing pressures were of the same magnitude as in the previous studies although during the opening phase of the chewing cycle they rose to levels above those previously found (Thüer et al., 1985; Thüer and Ingervall, 1986) with treatment.

The upper swallowing pressure was of the same magnitude as in previous studies of children (Thüer $e t$ al., 1985; Thüer and Ingervall, 1986) and young adults (Gould and Picton, 1964, 1968; Luffingham, 1969). The lower lip swallowing pressure was higher than in a previous study of children (Thüer et al., 1985) and in the studies of adults cited. In these studies, however, the swallowing of water was recorded. In the present investigation, the swallowing after chewing was recorded, which obviously results in greater pressure from the lower lip. The lower lip swallowing pressure in this study was thus not much different from that in a previous investigation in children of swallowing of bread (Thüer and Ingervall, 1986). That the lip pressure varies with the medium being swallowed has previously been reported by Proffit et al. (1975), who studied the swallowing of water and of saliva. Another factor that may have contributed to the large lower lip swallowing pressure was the large overjet of the subjects studied. It is possible that the lower lip gets trapped behind the upper incisors in such subjects during swallowing.

The lower lip chewing pressure and the lip strength behaved similarly during the period of observation. It is thus tempting to relate the changes in lip pressure to those in lip strength. However, the overjet also changed continuously during the study. The variations in lower lip chewing pressure may, thus, also be related to those in overjet or may be unrelated to the other variables. A factor arguing against the dependence of the lower lip chewing pressure on the lip strength is the fact that no correlation between lip strength and lip pressure was found in a previous study (Thüer and Ingervall, 1986). Correlation coefficients between the differences in lower lip chewing pressures and the differences in lip strength and in overjet were calculated. The differences examined were those between the findings before and at the end of treatment, and between the end of treatment and the follow-up recording, respectively. None of these correlation coefficients approached significance. It seems, therefore, that the variables vary independently.

For the position of the teeth, the pressures from the resting soft tissues are considered to be of greatest importance (Proffit, 1978). The fact that the resting lip pressures were unaffected by the increase in lip strength helps to explain why the improvement of upper incisor position obtained from the treatment was only partly stable during the control period. This study has thus shown that lip training with an oral screen has only a limited duration of influence on lip strength (in the time perspective studied) and that an increase of lip strength has no effect on the resting lip pressures on the teeth. The temporary increase in lip strength is, thus, not a factor that can retain the improved position of the maxillary incisors. 


\section{Address for correspondence}

Dr Urs Thüer

Klinik für Kieferorthopädie

Freiburgstrasse 7

CH-3010 Bern

Switzerland

\section{Acknowledgements}

This study was supported by Schweizerischer Nationalfonds zur Förderung der wissenschaftlichen Forschung, Grant No. 3.905-0.85.

\section{References}

Bergersen E O 1988 A longitudinal study of anterior vertical overbite from eight to twenty years of age. Angle Orthodontist 58: 237-256.

Fleming H B 1961 An investigation of the vertical overbite during the eruption of the permanent dentition. Angle Orthodontist 31: 53-62

Gould M S E, Picton D C A 1964 A study of pressures exerted by the lips and cheeks on the teeth of subjects with normal occlusion. Archives of Oral Biology 9: 469-478

Gould M S E, Picton D CA 1968 A study of pressures exerted by the lips and cheeks on the teeth of subjects with Angle's class II division 1, class II division 2 and class III malocclusions compared with those of subjects with normal occlusions. Archives of Oral Biology 13: 527-541

Ingervall B, Janson T 1981 The value of clinical lip strength measurements. American Journal of Orthodontics 80 : 496-507

Ingervall B, Eliasson G-B 1982 Effect of lip training in children with short upper lip. Angle Orthodontist 52: 222-233

Janson T, Ingervall B 1982 Relationship between lip strength and lip function in posture and chewing. European Journal of Orthodontics 4: 45-53

Luffingham J K 1969 Lip and cheek pressure exerted upon teeth in three adult groups with different occlusions. Archives of Oral Biology 14: 337-350
Lundström A 1948 Tooth size and occlusion in twins. S Karger, Basel, New York

Moyers $R$ E, van der Linden F P G M, Riolo $\mathbf{M ~ L , ~}$ McNamara J A, Jr 1976 Standards for human occlusal development, Craniofacial growth series, Monograph Number 5. Center for Human Growth and Development, University of Michigan, Ann Arbor, Michigan

Owman-Moll P, Ingervall B 1984 Effect of oral screen treatment on dentition, lip morphology, and function in children with incompetent lips. American Journal of Orthodontics 85: $37-46$

Posen A L 1972 The influence of maximum perioral and tongue force on the incisor teeth. Angle Orthodontist 42: 285-309

Posen A L 1976 The application of quantitative perioral assessment to orthodontic case analysis and treatment planning. Angle Orthodontist 46: 118-143

Proffit W R 1978 Equilibrium theory revisited: Factors influencing position of the teeth. Angle Orthodontist 48: 175-186

Proffit W R, McGlone R E, Barrett M J 1975 Lip and tongue pressures related to dental arch and oral cavity size in Australian Aborigines. Journal of Dental Research 54: $1161-1172$

Riolo M L, Moyers R E, McNamara J A, Jr, Hunter W S 1974 An atlas of craniofacial growth, Cephalometric standards from the University school growth study, University of Michigan, Craniofacial growth series, Monograph Number 2. Center for Human Growth and Development, University of Michigan, Ann Arbor, Michigan

Sinclair P M, Little R M 1985 Dentofacial maturation of untreated normals. American Journal of Orthodontics 88: $146-156$

Thüer U, Janson T, Ingervall B 1985 Application in children of a new method for the measurement of forces from the lips on the teeth. European Journal of Orthodontics 7:6378

Thüer U, Ingervall B 1986 Pressure from the lips on the teeth and malocclusion. American Journal of Orthodontics 90: 234-242

Vig P S, Cohen A M 1979 Vertical growth of the lips: A serial cephalometric study. American Journal of Orthodontics 75: $405-415$ 